\title{
Invasive treatment to control neuropathic pain
}

\author{
Tratamento invasivo para o controle da dor neuropática \\ José Oswaldo de Oliveira Júnior ${ }^{1}$, Cláudio Fernandes Corrêa² ${ }^{2}$ Jânio Alves Ferreira ${ }^{3}$
}

DOI 10.5935/1806-0013.20160059

\section{ABSTRACT}

BACKGROUND AND OBJECTIVES: Distress, allied to neuropathic pain persistence and its refractory nature, often leads patients to accept invasive procedures. Neuropathic pain control is a major medical challenge requiring approaches and decisions especially based on effectiveness, risks and costs. This study aimed at reviewing these aspects related to major invasive procedures.

CONTENTS: Major invasive procedures to control neuropathic pain are presented. Initially, classically reversible anesthetic blocks; then invasive neuromodulation techniques using electric current application and the magnetic field generated by it becomes a target to be stimulated, inhibited or modified in the nervous system (central, peripheral or autonomic); and, finally, ablative procedures including anesthetic methods administering neurolytic agents rather than anesthetics and neurosurgeries using different methods to injure the nervous system to control painful neuropathic discomfort.

CONCLUSION: Patients eligible to invasive procedures to control neuropathic pain have, in addition to pain itself, a mixed distress including the collection of repeated delusions at every treatment failure. They have reserved prognosis with regard to total cure and, unfortunately, relieve obtained with invasive treatment in general does not reach persistent and high rates. In such adverse situation, these partial results of decreasing original pain intensity may be interpreted as acceptable, provided the impact on final quality of life is positive. Maybe, the rare exceptions are good results obtained with typical idiopathic/cryptogenic neuralgias ironically excluded from the stricter interpretation of the new pathophysiologic classification of neuropathic pains.

Keywords: Anesthetic blocks, Cordectomy, Cortical electrical stimulation, Deep electrical brain stimulation, DREZotomy, Invasive neuromodulation, Medullary electrical stimulation, Neurolytic blocks, Neuropathic pain, Neurosurgery for neuropathic pain, Spinal drugs

\section{RESUMO}

JUSTFICATIVA E OBJETIVOS: O sofrimento aliado à persistência e refratariedade da dor neuropática frequentemente leva seu portador a aceitar tratamentos invasivos. O controle da dor neuropática representa um desafio médico importante necessitando adoçáo de condutas e decisōes baseadas, principalmente, em efetividade, riscos e custos. O escopo deste estudo foi a revisão desses aspectos relacionados aos principais procedimentos invasivos

CONTEÚDO: São apresentados os principais procedimentos invasivos utilizados para o controle da dor neuropática. Inicialmente, os bloqueios anestésicos, classicamente reversíveis; depois as técnicas de neuromodulação invasiva que utilizam a aplicação de corrente elétrica e o campo magnético por ela gerado em alvos a serem estimulados, inibidos ou modificados, no sistema nervoso (central, periférico ou autônomo); e, finalmente, os procedimentos ablativos que incluem os métodos anestésicos que administram agentes neurolíticos ao invés de anestésicos, e, as neurocirurgias que utilizam métodos diversos de produçáo de lesóes no sistema nervoso para o controle do desconforto doloroso neuropático.

CONCLUSÃO: Os pacientes que se apresentam como candidatos a receberem

1. Escola Cancerologia Celestino Bourroul, Departamento de Terapia Antálgica, Cirurgia Funcional E Cuidados Paliativos da Fundação Antênio Prudente, São Paulo, SP, Brasil.

2. Hospital Nove de Julho, Centro de Dor e Neurocirurgia Funcional, Sáo Paulo, SP, Brasil.

3. Hospital Antônio Cândido Camargo, Central da Dor e Estereotaxia, Sáo Paulo, SP, Brasil.

Conflicts of interests: none - Sponsoring sources: none.

\section{Correspondence to:}

José Oswaldo de Oliveira Júnior

Rua Pedroso Alvarenga, 1062, conjunto 55, 5a andar

04531-004 Sáo Paulo, SP, Brasil.

(C) Sociedade Brasileira para o Estudo da Dor indicaçóes de procedimentos invasivos para controle de dores neuropáticas, possuem além do inerente à própria dor, sofrimento misto, que inclui a coleção de desilusóes reiteradas a cada insucesso de tratamento. Possuem prognóstico reservado no que tange a plena cura, e, infelizmente, o alívio obtido com o tratamento invasivo, em geral, não atinge taxas persistentes e elevadas. Nessa situação tấo adversa esses resultados parciais de reduçáo da intensidade da dor original possam ser interpretados como aceitáveis desde que o impacto na qualidade de vida final seja positivo. Talvez, as raras exceçôes, recaiam sobre os bons resultados obtidos com as neuralgias típicas, idiopáticas/criptogenéticas, ironicamente, excluídas da interpretaçáo mais rígida da nova classificação fisiopatológica das dores neuropáticas.

Descritores: Bloqueios anestésicos, Bloqueios neurolíticos, Cordotomia, Dor neuropática, DREZotomia, Fármacos subaracnóideo, Estimulação elétrica cerebral profunda, Estimulação elétrica cortical, Estimulação elétrica medular, Neurocirurgia para dor neuropática, Neuromodulação invasiva.

\section{INTRODUCTION}

The vast majority of invasive procedures to relief neuropathic pain (NP) aim at symptomatic, rather than etiologic control ${ }^{1}$.

The idea of controlling pain by solving its cause permeates lay understanding and interferes with the acceptance of exclusively symptomatic treatment, especially when invasive procedures are proposed.

Additionally, the search for pain of ZERO intensity is a dreamlike expectation of patients, relatives and caregivers. In chronic, especially atypical, NP treatment, the objective is to improve quality of life (QL) and not the total disappearance of the complaint. In fact, the objective would be close if patients could obtain decreased intensity, long painless periods and a moment of some days when they would forget pain. The exception is the group of typical intermittent neuropathic pains, which may be controlled and ceased for long periods with pharmacological treatment and, when necessary, the same might be obtained with invasive procedures.

Didactic task is necessary in the clinical practice, as well as the conciliation of expectations, that is, between what the medical team can offer and what patients, caregivers and relatives expect and demand.

Invasive procedures may be ablative when, fundamentally, do not preserve nervous system (central and/or peripheral); and non-ablative when preserving.

The recognition of a functional solidarity uniting neurons ${ }^{2}$ and, more recently, also neuroglial cells, gives subsidies for discomfort following invasive procedures for pain relief. So, non-ablative procedures are being increasingly preferred since ablative procedures are associated to further neuropathic discomfort or to worsening of those symptoms already being treated ${ }^{1}$.

\section{ANESTHETIC PROCEDURES}

Local anesthetics and opioids may be used in the pharmacological blockade of nociceptive pathways with analgesia also for NP3. Simultaneous use of two drugs in a blockade may add to and potentiate effects. Commonly used substances for such blocks are procaine, lidocaine, prilocaine, bupivacaine and ropivacaine ${ }^{3}$. Most of the times they are topically applied or administered close to nervous trunks, plexuses, nervous roots, spinal spaces (epidural and spinal) and, in specialized pain therapy centers, also by systemic route in doses close to those used to control arrhythmias.

Anesthetic block provides information for diagnosis and prognosis, in addition to having therapeutic objectives in some cases. Blockade provides reversion, at least temporary, of situations such as allodynia and hyperalgesia. Its usefulness for non-cancer short-lasting pain is unques- 
tionable, even when there is predominance of the neuropathic component. In many patients, myofascial pain, called corollary of those directly related to baseline disease, respond very well to muscle triggerpoints blocks and to complementary physical medicine approach.

Myofascial pain often mimics neuropathies, suggests irradiation, when in fact it is referred, induces numbness and loss of strength sensations, may be paroxysmal, is reported as jumping, pricking, shocks and very often is associated to burning sensation. When pain is secondary to pain-muscle spasm vicious cycle (myofascial syndrome), relief might be very prolonged.

The combination of anesthesia and physiatry is an effective binomial for numerous pains, including neuropathic pain. Blockades release body parts for rehabilitation activities which otherwise would remain in antalgic immobility perpetuating and worsening pain.

Blockades are useful to minimize discomfort of numerous therapeutic procedures such as change dressings, relieving puncture of cysts and abscesses, fractures and luxations reductions, among others.

Many patients may have their pain temporarily minimized while waiting for specific therapeutic procedures. When opioid is used for blockade, most commonly used drugs are morphine and fentanyl (and their counterparts) and may be administered by infiltrations close to nervous structures, as already described, or in the central nervous system (epidural, spinal and ventricular).

Opioid blockade induces prolonged analgesia and does not interfere with motor activity; although it may change respiratory pattern and urinary control. Doses are in general very low, even for tolerant patients ${ }^{3,4}$. NP control requires higher opioid doses. Delay in opioid titration and increasing incidence of dose escalation may suggest poor or inadequate response and induce changes in the approach contemplating drug replacement.

Temporary or permanent catheter implants, with or without bacterial filters, with or without subcutaneous access chambers for new infiltrations, are useful when the aim is continuous blocks ${ }^{4}$.

In painful diseases with exacerbated autonomic component, patients might be submitted to sympathetic ganglia blocks. Stellate ganglion block may promote better peripheral perfusion, increased algiogenic substance clearance and decreased spontaneous activity in spinal cord posterior horn, peripheral axonal and in receptors ${ }^{3,5}$. They are useful in cases of complex regional pain syndromes and other cranial, cervical, facial and brachial sympathetic dysautonomias. Neuropathic pains, such as postherpetic neuralgias, with the same mentioned distribution, may also be controlled with repetition serial blocks. Sympathetic blockades may also be performed in other nervous system points with the same easiness and analgesic efficiency.

When the aim is prolonged anesthesia or analgesia with no need for reinfiltrations, neurolytic agents may be used with or without previous test with anesthetic agents. Commonly used neurolytic agents are alcohol and phenol. Neurolytic agent diffusion may be forecasted by studying the distribution of contrast in imaging exams, however in practice there might be discrepancy and involvement of neighbor nervous structures. When just autonomic components are injured, there is no neuropathic discomfort, however the opposite might be true in case of injuries associated to somatic nerves ${ }^{5}$.

Pre-neuropathic conditions, such as subclinical presentations (or oligosymptomatic) of diabetic, actinic, chemotherapeutic and traumatic neuropathies, among others, are predisposing factors and increase the risk of additional neuropathic pain. Most precise injuries where limits have to be respected (such as when targets are sensory cranial nerves, CSF space sensory roots), are not usually chemically treated, but rather by radiofrequency, cryocoagulation, radiosurgery, or even open surgery with microbipolar or microknife.

Some patients with chest cancer pain with brain metastases are unable to get analgesia by means of cordotomies and epidural catheters due to the risk of intracranial pressure decompensation. In these cases, a possibility for analgesia (unilateral) is catheter insertion in the interpleural space. Analgesic solution, made up of local anesthetics and opioids, is administered at regular intervals, by patients or caregivers, by means of a catheter protected with bacterial filter. Some inconvenients are to be remembered with this type of blockade: the volume of each injection is important (30 to $40 \mathrm{~mL}$, never less than $20 \mathrm{~mL}$ ) and blood levels reached after injection are expressive.

Anesthetic blocks may trigger neuropathic discomfort by the quantitative and qualitative change in sensory afference. Pain complaints are not uncommon during spinal anesthesia recovery period. Those with spinal analgesic release systems may have neuropathic pain relief by eliminating local anesthetics from the solution or the mixture being used.

\section{NEUROSURGICAL PROCEDURES}

In the last decades, due to the development of more potent drugs, with more adequate selectivity, pharmacokinetics and pharmacodynamics, indication of surgical procedures to control pain has become naturally less frequent. Surgical procedures, however, are still useful for a considerable number of cases refractory to drug therapy, both by analgesic response failure and adverse effects not tolerated by patients. Improved knowledge about painful syndromes, the development of new techniques and the improvement of existing ones, as well as the refinement of their indications, have contributed a lot for the adequacy and efficacy of surgeries ${ }^{6}$.

Diagnosis review of the pain syndrome or associated diseases is critical before applying a therapeutic, especially surgical, technique. Wrong diagnosis is frequent cause of refractoriness to treatment. Clinical history, detailed neurologic exam and complementary exams should be applied before each proposal. In addition to the diagnosis of each painful syndrome involved in patients' pain, be it neuropathic, non neuropathic, specific painful syndrome (e.g., trigeminal neuralgia) or the coexistence of many of them; correct pain topography and possible involvement of the central or peripheral nervous system, visceral or somatic, are critical for the adequate choice of the functional neurosurgical procedure ${ }^{6-8}$.

There are several surgical pain treatment modalities which shall be applied according to painful syndrome diagnosis. Among them, repairing surgeries, such as nervous decompression; ablation, inactivation or blockade of specific points of projection pathways or nervous centers related to pain processing; spinal drug administration by means of infusion system implants; spinal and supraspinal pain inhibiting systems with neuromodulator implants with spinal or brain electrodes ${ }^{7}$.

Neuropathic pain may be treated with neurosurgical methods, depending on the complexity and etiology of pain. In cancer patients, the indication of more invasive procedures for adequate pain control, including neuropathic pain, shall not be delayed, since this control leads to significant improvement in their QL, especially for those with advanced disease and reserved prognosis ${ }^{8,9}$.

Neurosurgical technique shall be chosen as from the understanding of the pathophysiology and topography of neural structures involved with pain in the specific case. Neurosurgical treatment by interrupting nociceptive pathways should be performed when pain is predominantly induced by excessive nociceptive stimulation. This is an ablative method and, as such, brings significant changes to locoregional and distant nervous system ${ }^{2,8}$.

Currently, with the adequate diagnosis of pain afflicting patients, it is possible to select, in most cases, the best clinical or surgical treatment based on reliable review data, that is, based on evidences. Surgical treatment is not necessarily indicated as the last alternative after all conservative treatment measures are depleted.

Neurosurgical interruption of nociceptive pathways may be obtained at any central or peripheral nervous system level. Surgery may be open or percutaneous.

Percutaneous procedures are less invasive, safer and more precise, of low operational cost, are not associated to complications inherent to conventional procedures. However, for needing patients' cooperation during partial or total time of its performance, sometimes the psychoaffective component of the percutaneous and cooperating technique is replaced by tissue trauma of the open and unconscious method.

To minimize lucidity suffering during percutaneous surgeries, drugs are administered to induce anterograde and retrogade amnesia. More and more, procedures are enriched with neurophysiologic and neuroimaging data so as to decrease patients' participation time.

Pathways may be interrupted with chemical injury with neurolytic agents, thermal of criocoagulation or thermocoagulation devices, ischemic by mechanical compression, and even actinic with the combina- 
tion of stereotactic and multicolimated radiotherapy methods ${ }^{6-9}$. Neuroradiological studies, from simple X-rays, computerized tomography radioscopy, and more recently MRI and ultrasound images, may be used in the pre, peri and postoperative periods of such procedures.

\section{ABLATIVE METHODS}

Ablative methods aim at interrupting pain pathways by deliberate and selective injury of structures such as peripheral nerves, nervous roots and ganglia, medullary cords and ascending structures and brain structures such as thalamus nuclei or midbrain. Limbic system structures injury also acts to decrease pain-associated cognitive and emotional components, which cause suffering to individuals.

Percutaneous neurosurgery under sedation is safer than open surgeries, in addition to allowing the physiological mapping of the desired target and simulation of postoperative situation. Neurolytic substances involve complications (less frequent, such as sympathectomies), being safer the use of physical media such as cold (criocoagulation) or the most commonly used due to further availability, heat (radiofrequency) to interrupt nervous pathways and centers ${ }^{6,7,8,9}$.

\section{SYMPATHECTOMIES}

Their primary indications are to treat visceral pain of abdominal, pelvic and chest cavities, and ischemic pain. Predominantly neuropathic pains are not classically included among indications. They should only be indicated when there is significant and temporary pain relief after sympathetic chain blocks with local anesthetics, being contraindicated for CRPS, amputation stump pain, myelopathic pain, cauda equina injury pain, roots avulsion and postherpetic neuralgia ${ }^{4,6}$.

\section{PERIPHERAL NEUROPATHIES (SOMATIC NERVES)}

Neurotomies might be useful to control neuropathic pain. They are indicated to treat occipital neuralgia, genitor-femoral, ilieo-inguinal cutaneous-femoral nerve, lesser sciatic and pudendal neuralgia. They are not effective for most patients with deafferentation pain, root avulsion pain, amputation stump pain and postherpetic neuralgia.

Neurotomy of spinal roots posterior recurrent branches consists in their injury where they emerge in conjugate foramen, both by open and percutaneous procedure, by the introduction of an electrode along the external border and on joint facet base, followed by radiofrequency injury of such nerves. It is effective to treat pain secondary to facet arthropathy, paravertebral myofascial painful syndromes refractory to physiatric procedures and apendicular neuropathic pain. However, best results are obtained for axial-type nociceptive pain ${ }^{10}$.

Peripheral neurotomies have anti-inflammatory effect by decreasing neurogenic inflammation dependent on algiogenic substances release in the periphery. Radiculopathic pain is relieved by spinal cord afference inhibition. This inhibition decreases the recruitment of second order of convergence wide dynamic range neuronal units. It promotes pain relief in $50 \%$ of cases after 8 to 27 months of treatment, with best results in patients not previously submitted to spinal surgery. They seldom develop additional neuropathic painful discomfort or to replace original pain $^{10}$.

Neurotomy or neurectomy of trigeminal nerve peripheral branches may be performed in several ways. Avulsion, crushing, interposition of organic material between sectioned stumps, mechanical neurolysis and retrograde folding of amputated nervous stumps may provide benefit to patients, however only temporary due to nervous regeneration phenomenon.

Neurectomy of trigeminal nerve peripheral branches has indication restricted to diagnostic confirmation, to treatment of elderly or debilitated patients or with lateral neuralgia, when there is anesthesia of one hemiface secondary to contralateral rhyzotomy.

Percutaneous neurotomy of occipital nerves is a useful procedure in cases of greater occipital nerve neuralgia. It is perfomed by percutaneous puncture of occipital nerves at occipital bone squama, close to occipital artery. Chemical neurolysis is no longer used, being replaced by radiofrequency. However, neurotomy results fall short of those obtained by anesthetic blocks (false-positives).

Pudendal nerve neurotomy is indicated to treat pudendal nerve neuralgia and perineal pain (especially cancer pain). It consists in the percutaneous introduction of electrode in posterior perineal region, followed by stimulation and radiofrequency injury of pudendal nerve trunk. When procedure is bilateral, it may result in urinary incontinence. Chemical injuries (in general with phenol) may be performed by the same anterior route used for local anesthesia in episiotomies.

Genito-femoral nerve neurotomy is indicated in cases of genito-femoral nerve neuralgia, while ileo-inguinal neurotomy is indicated to treat ileo-inguinal neuralgia. They are performed by retro-peritoneum access, similar to that used for lumbar sympathectomy.

Cutaneous-femoral nerve neurotomy is indicated to treat paresthetic meralgia. Nerve is accessed by medial incision of the antero-superior iliac spine.

Lesser sciatic nerve neurotomy is indicated for neuralgia of such structures. Nerve is accessed by incision of gluteal region and proximal region of thigh posterior face, after gluteus minimus muscle dissecation.

\section{RHYZOTOMIES}

True rhyzotomies are uncommon. Procedures, in their vast majority, are in fact neurotomies. In the spine they are in general spinal neurotomies since the target is distal to sensory ganglia, in mixed nerves.

They are indicataed to treat pain induced by paroxysmal neuralgias or by tumors, in restricted body areas, especially face, brain, cervical, thoracic and perineal regions. They are contraindicated for amputation stump pain, postherpetic neuralgia, actinic neuropathy, myelopathic pain or cauda equina pain, nervous roots avulsion, atypical facial pain and painful facial anesthesia.

Cervical, thoracic and sacral rhyzotomy is effective for selected oligosegmental paroxysmal peripheral NP cases, restricted to superficial body areas and few dermatomes. In limbs, rhyzotomies may induce sensory ataxia. Sacral rhyzotomy should not bilaterally involve second sacral roots in patients with functional bladder integrity due to the risk of developing neurogenic bladder. Intercostal rhyzotomy may benefit some patients with intercostal neuralgia.

Trigeminal, glossopharyngeal and intermediate nerves rhyzotomy is effective to treat pain resulting from essential neuralgias ${ }^{11-13}$ and from face, pharynx, tonsillar pouch, tongue base and inner ear pain. Open spinal and trigeminal nerve rhyzotomies are seldom indicated today ${ }^{14}$. Intermediate nerve rhyzotomy is still an open procedure by microsurgical technique. Percutaneous procedures are more often used for such objective.

Trigeminal nerve rhyzotomy consists in the manual introduction of an electrode, by anterior route, by means of oval foramen, inside Gasser ganglion, under radiological, radioscopic or tomographic control ${ }^{10,12}$. After puncture, patients are awakened and questioned about the location of the paresthetic sensation evoked by trigeminal structures stimulation. Based on this information, the electrode is moved until paresthetic sensation is located in the pain territory.

Thermal injuries are repeated during 60-minute periods with increasing intensity until hypoalgesia or analgesia with preservation of segmental tactile sensitivity is obtained by radiofrequency generators. Temperature monitoring quantifies the level of induced injury. Although consecrated, the name trigeminal rhyzotomy is mistaken for starting from the wrong assumption that the surgical target is a root, when in fact it is cranial nerve divisions ${ }^{11,12,13}$.

Radiofrequency percutaneous rhyzotomies are performed under general anesthesia or sedation. Preanesthetic medication (lorazepam, flunitrazepam) induces amnesia and short-lasting anesthetic agents (propofol) or neuroleptoanalgesics (fentanyl, droperidol) are recommended for the procedure. In the last decades, the use of $\mathrm{a}_{2}$-adrenergics, such as dexmedetomidine, may provide good analgesia, sedation and cooperation conditions. When patients tolerate the discomfort, injuries are performed without general anesthesia; otherwise additional anesthetic doses are administered. When induced sensory deficit is not in the adequate territory, electrode is repositioned and new radiofrequency injuries are produced.

There is face numbness in almost all cases. Paresthesias are observed in 
$8 \%$ to $10.9 \%$ of patients and painful dysesthesias in $0.5 \%$ to $5 \%$ of cases. In average, there is pain recurrence in $5 \%$ of patients in the first year, in $10 \%$ in the second year and, progressively, in $5 \%$ of cases per year. Recurrence rate may be higher in trigeminal neuralgias associated to demyelinating disease (multiple sclerosis) reaching up to $40 \%$ in two years. Trigeminal nerve rhyzotomy with embolectomy baloon compression consists in percutaneous Gasser ganglion puncture under trunk, systemic or intravenous anesthesia, with or without artificial ventilation. Then, balloon is inflated on the ganglion by means of a needle which leads the catheter, lasting 60 seconds and with 0.6 to $0.8 \mathrm{~mL}$ of iodized contrast ${ }^{13}$.

Gloosopharyngeal nerve rhyzotomy is similarly performed and after torn foramen puncture. There might be bradycardia and hypotension during intervention which indicates to need to interrupt the injury. Sensory and motor sequelae, including dysphonia, dysphasia and dysphagia are referred in some cases. Pain recurrence is uncommon and there is mortality in $5 \%$ of cases.

\section{LISSAUER TRATOTOMY AND SPINAL CORD POSTERIOR HORN INJURY (SCPH) OR INJURY OF DORSAL ROOTS ENTRY ZONE (DREZ OR DREZOTOMY)}

This is radiofrequency lysis of Lissauer tract and of spinal cord posterior horn gray matter where there is neuronal hyperactivity in cases of deafferentation or spasticity pain. It is performed to treat phantom limb pain, pain resulting from actinic plexular neuropathies, cancer and trauma pain, postherpetic neuralgia, myelopathic pain, cauda equina injury and spasticity pain, nervous roots avulsion pain and atypical face neuralgia. It has no satisfactory results in complex regional pain syndrome and in patients with multiple sclerosis-associated pain ${ }^{15,16}$

The procedure decreases hyperactivity of nociceptive pathways of spinal cord ascending tracts because it destroys hyperexcited neurons of SCPH laminae 1, II, III, IV, V and VI and Lissauer tract which are involved in facilitation and inhibition mechanisms of SCPH neurons activity, as well as ascending pathways traveling through spinal cord posterolateral quadrant. This allows changing the balance between excitatory and inhibitory pathways of deafferented segmental neuronal circuits. Lissauer tract and SCPH injury is more effective and safer when indicated to treat patients with extensive deafferentation areas, such as brachial plexus roots avulsion, actinic plexular neuropathy, segmental pain in paraplegic patients with myelopathy or with cauda equina and conus injury $15-17$.

General anesthesia and laminectomy are needed for spinal procedure, to expose roots penetration zone correponding to innervation of areas where pain is referred, as well as neighbor rostral and caudal dermatomes. Dura is opened in the medial line and root entry zone is exposed by means of surgical microscope. In cases of brachial plexus avulsion, disposition of contralateral roots and of ipsilaeral roots penetration line are the anatomic repairs to locate spinal cord areas to be injured. Dermatomes are located by motor roots (contralateral, if necessary) monopolar electrical stimulation.

Electrodes are implanted in spinal cord and directed with 25 degrees inclination from outside to inside and from back to forth, in transversal plane, penetrating $2 \mathrm{~mm}$ in the depth of each pain reference segment. Then, thermal injuries are performed by radiofrequency at every $2 \mathrm{~mm}$. In case of traumatic myelopathy, they are performed in the entry zone of the three roots located above the anatomically abnormal segment. Preoperative sensory deficit extension and intensity are systematically increased after Lissauer tract and SCPH injury. Motor deficit, in general mild, is present in approximately $10 \%$ of patients submitted to Lissauer tract and SCPH injury ${ }^{15-17}$. Discrete and transient posterior cord syndrome homolateral to the injury is initially seen in $2 / 3$ of cases, being permanent in $10 \%$ to $30 \%$. Paresthesia in neighbor dermatomes region, and hyperesthesia in the transition area between normal and impaired regions are also observed.

There is higher risk of long tracts injury in cases of avulsion due to spinal cord atrophy as consequence of traumatized tissue healing scar. There is higher possibility of neurological function impairment when injury is performed in spinal cord thoracic segments. Numerous neurological complications have been described after this procedure indicated to treat post-lumbar laminectomy syndrome, among them genital region and lower limbs hypoesthesia, motor deficits, sphincter incontinence and sexual impotency.

For nervous roots avulsion, immediate excellent and good results were observed in $64.7 \%$ to $100 \%$ of patients, and regular results in $8.3 \%$ to $24 \%$. During follow up period varying between 5 and 108 months, there is decrease in good and excellent results to $50 \%$ to $81 \%$ and increase in the number of regular results of $9.5 \%$ to $40 \%$. Initial improvement is maintained after treatment in most patients with actinic neuropathyassociated pain. There is $75 \%$ to $100 \%$ improvement in patients with postherpetic neuralgia immediately after procedure. With time, there is partial or complete pain recurrence in up to $50 \%$ of patients in 6 months, in $38 \%$ in one year and in $26 \%$ in 18 months. Recurrent pain after surgery in these cases is different from original pain in $50 \%$ of cases. Original burning sensation is replaced by aching, throbbing or cold sensation ${ }^{6,15}$. For phantom pain there is immediate improvement in $50 \%$ to $100 \%$ of patients soon after procedure and in the long term in 50 to $66 \%$. Results seem to be more unsatisfactory to treat amputation stump pain ${ }^{6,15}$. The procedure chronically benefits $45.5 \%$ to $80 \%$ of patients with traumatic myelopathic pain with good initial results in $85 \%$ to $100 \%$. There is significant segmental myelopathic pain improvement in $80 \%$ of patients, of unilateral pain in $90 \%$ and of distal and sacral pain in just $32 \%$.

There is also relief of pain generated by trigger-zones stimulation. Results are considered unsatisfactory in less than $41 \%$ of patients. No significant improvement has been observed in multiple sclerosis patients.

\section{STEREOTACTIC NUCLEOTRACTOTOMY OF TRIGEMINAL NER- VE SPINAL TRACT}

This is stereotactic injury of the trigeminal nerve spinal tract oval portion, being indicated for deafferentation facial pain which does not improve after caudal nucleotractotomy ${ }^{18,19}$.

The technique is performed with patients in the sitting or lateral position, under local anesthesia. It consists in bone fixation of the stereotactic device to the cephalic segment, followed by stereotomography and reconstruction of bulbo-spinal transition images, with merging of obtained images with the stereotactic atlas. Stereotactic target is placed 4 to $6.5 \mathrm{~mm}$ laterally to median line, according to the affected territory of third or first trigeminal nerve division, upwards and from outside to inside, with 20 degrees inclination with relation to transversal and sagital planes.

Location is confirmed with monopolar stimulation. When the electrical stimulation induces discomfort in referred pain site, radiofrequency sessions are performed to coagulate neural tissue, with $2 \mathrm{~mm}$ diameter. This procedure is markedly effective for trigeminal postherpetic neuralgia and other deafferentation pains located in the face and for orofacial cancer pain.

Trigeminal nucleotractotomy may be an open procedure. Surgical and anesthetic size is higher and might not be indicated for elderly or debilitated patients. However, vascular injuries may be efficiently prevented by direct view. Postero-inferior cerebellar artery inferiorly surrounds cerebellar hemispheres and may be injured by the procedure causing bleeding, spasms or coagulation. Arterial injury is more common in stereotactic procedures. Open injuries, on the other hand, do not allow physiologic mapping and control of its magnitude. Injuries extension may lead to impairment of posterior funiculi and spinothalamic tracts. Defficiencies are often permanent, but not disabling, in $40 \%$ of patients treated with open trigeminal nucleotractotomy, and in $20 \%$ of patients treated with the stereotactic technique. The association of microendoscopy and stereotaxis has increased the advantages of this method as compared to open procedures ${ }^{3,6,18}$. A recent study confirms the long duration (mean of 4.3 years) of good results obtained in atypical trigeminal chronic pain, brachial plexus avulsion, postherpetic neuralgia and phantom limb pain ${ }^{19}$.

\section{PONTINE TRIGEMINAL NUCLEOTRACTOTOMY}

Effective procedure to treat deafferentation facial pain which has not improved after caudal nucleotractotomy. It improves pain in approxi- 
mately $60 \%$ of patients with atypical facial pain ${ }^{18,20-22}$.

Trigeminal nerve spinal tract nucleotractotomy and stereotactic pontine trigeminal nucleotractotomy are effective to treat deafferentation facial pain (Wallemberg syndrome, trigeminal neuropathy pain). Immediate excellent results in cases of postherpetic neuralgia in the trigeminal nerve territory were observed in $57 \%$ to $100 \%$ of cases. During the follow up period, from 6 to 72 months, pain was absent in $25 \%$ to $50 \%$ of patients and had improved in $31 \%$ to $50 \%$. Results seem to be less satisfactory with increasing number of impaired divisions. There are evidences that paroxysmal pain is more easily controlled as compared to constant weight pain. There is improvement in actinic trigeminal neuropathy in most treated patients. There is also symptoms improvement in more than $50 \%$ of patients with painful facial anesthesia. Results are unsatisfactory for patients with weight pain.

Pontine trigeminal tractotomy was used as adjuvant method in a series of 50 patients with typical trigeminal neuralgia refractory to conservative treatment, where neuroimaging investigations have not shown evident vascular conflict, and the same findings were observed in intraoperative retrosygmoid exploration. Just one patient $(2 \%)$ has not improved, while $18 \%$ have reported partial improvement and $80 \%$ total pain remission ${ }^{21}$. Trigeminal neuralgia and multiple sclerosis patients have reported $87.5 \%$ of good results ${ }^{21}$.

\section{CORDOTOMY}

It consists in spinothalamic tract interruption in spinal cord anterolateral quadrant, contralateral to that where pain is referred ${ }^{22,23}$.

Antero-lateral cordotomy is indicated to treat cancer pain with less than one-year survival, which unilaterally affects distal to cervical rostral segments. It should be avoided in patients with ventilation abnormalities. It may also control mixed cancer pains (by increasing nociception and neuropathic) ${ }^{22}$. It has unsatisfactory results when performed in patients with actinic pain, postherpetic neuralgia, nervous roots avulsion, phantom pain and amputation stump pain ${ }^{24}$.

Percutaneous cordotomy is performed in the cervical region (between $\mathrm{C}_{1}$ and $\mathrm{C}_{2}$ or $\mathrm{C}_{5}$ and $\mathrm{C}_{6}$ or $\mathrm{C}_{6}$ and $\mathrm{C}_{7}$ ) under local anesthesia complemented, if necessary, with intravenous agents for patients' comfort. After perimyelographic or stereotomomyelographic procedure, to delineate spinal cord and dentate ligament, an electrode is introduced by lateral or anterior route in spinal cord antero-lateral quadrant. After confirming location with electrical stimulation, spinothalamic tract is submitted to radiofrequency lysis. Endoscopic tools provide less surgical time, less radiological exposure and the performance in patients allergic to iodized contrasts ${ }^{24-26}$.

Open procedure consists in laminectomy and exposure of first and second cervical spinal cord segments or of second and third thoracic spinal cord segments and section of the antero-lateral quadrant of this nervous structure. In children, the procedure is in general performed under general anesthesia and as open procedure; however computerized tomography may offer safe conditions for the percutaneous method ${ }^{27}$.

In rare situations where there is indication for bilateral cordotomy, an interval of at least three weeks is recommended between procedures. Eventually, there might be pain contralateral to original pain after unilateral surgery, being very often necessary indication for contralateral procedure. Motor, sphincter and sexual deficits are present in less than $10 \%$ of cases. Cordotomy may induce myelopathic pain in up to $20 \%$ of patients followed up for long periods. Respiratory paralysis during sleep syndrome is uncommon and is manifested after bilateral cordotomies, especially when analgesia reaches higher dermatomes (brachial) ${ }^{22,26}$.

\section{EXTRALEMINISCAL MYELOTOMY}

It consists in the interruption of spinoreticulothalamic fibers crossing the midline toward spinal cord antero-lateral quadrants and going to supra-segmental structures. It is indicated for pelvi-perineal bilateral cancer pain or lower limbs pain in patients in whom bilateral cervical cordotomy poses risks. It results in bilateral suspended analgesia. It is also indicated to treat myelopathic pain, brachial plexus roots avulsion pain and postherpetic neuralgia. Median longitudinal myeolotomy, performed two to three segments above the level of the injury in cases of spinal injury pain, may temporarily relieve radicular pain and pain in the transition territory.

It may be an open procedure after thoracic and lumbar rostral laminectory, followed by spinal cord sagital division, or percutaneously, with stereotactic technique ${ }^{28}$. The latter consists in fixing the stereotaxis device to the skull and of imaging exams (cranio-cervical perimyelography, stereotomography, stereoresonance, or even combination by merging more than one). After delineating cervical cord contour, an electrode is introduced in the midline of the central portion of the transition between both nervous structures. Stimulation generates ascending heat sensation from the perineum to dorsal body areas. Interruption by radiofrequency of extraleminiscal spinothalamic pathways which project in brainstem reticular formation provides pain relief with preservation of superficial discriminative sensitivity.

\section{MESENCEPHALOTOMY}

Also known as midbrain rostral reticulotomy, it aims at interrupting spinoreticulothalamic pathways involved in paresthesia and dysesthesia in patients with both benign and malignant $\mathrm{NP}^{22,31,32}$

There might be prolonged improvement in $50 \%$ to $77.8 \%$ of NP patients submitted to mesencephalotomy during periods varying from 2 months to 8 years. In the long term, there is $20 \%$ to $66.7 \%$ relief and $30 \%$ improvement. Mesencephalotomy may provide relief in $50 \%$ to $70 \%$ of patients with painful facial anesthesia, of patiens with thalamic syndrome, of those with brachial plexus roots avulsion, in cases of phantom pain and amputation stump pain ${ }^{31-35}$.

Procedure consists in fixation, under local anesthesia, of a stereotaxis device to patients' cephalic segment. After stereotomography or stereoMR, anatomic targets are identified. By means of frontal or occipital perforation, an electrode is introduced and directed to the target. By means of this electrode, deep brain cellular activity is recorded and next there is electrical stimulation to delineate the structure to be surgically treated. Thermal radiofrequency injuries are then performed.

Mortality is around $7 \%$ to $8 \%$.

Most common mesencephalotomy complications are sleepiness and dyssynnergy of eye mobility and are, in general, temporary. During the first two or three days after surgery stimulants such as methylphenidate are extremely useful to decrease sleepiness. Complication which may be permanent in $30 \%$ of patients is paresis of conjugate gaze up. Dysesthesias are present in $4.3 \%$ to $50 \%$ of $\operatorname{cases}^{22,31-35}$.

\section{THALAMOTOMY}

This procedure consists in injuring spinothalamic and paleospinothalamic units by injuring nonspecific thalamic nuclei. It is indicated for nociception and deafferentation pain in broad body areas, especially when located in the cranio-cervical and brachial segment in patients were cordotomies are contraindicated ${ }^{22,36}$.

Injuries involve paleospinothalamic pathways and units, are broad and located in thalamic center-median, parafascicular, limitans and intralaminar nuclei (nonspecific thalamic nuclei), related to dysesthesic pain component.

Procedure consists in fixing the stereotaxis device to the cephalic segment and performance of stereotomographic or stereoMR exams for spatial delineation of brain structures, and of images merging with those of the stereotaxis atlas. Perioperative electroencephalogram allows the reading of thalamus-induced brain activity according to current and frequency intensity. Established targets are stimulated and injured by radiofrequency. In patients with unfavorable clinical conditions, some suggest radiosurgery ${ }^{37}$.

Thalamotomy temporarily relieves NP (peripheral neuropathies, myelopathies and encephalopathies) in $40 \%$ to $70 \%$ of cases, and in $90 \%$ in cancer-induced pain. Results, however are often unsatisfactory in the long term.

Complications, in general temporary, are present in $48 \%$ of cases, being primarily represented by sleepiness and dyssynergy of eye mobility. In $18 \%$ of cases there are permanent complications, especially after basal thalamotomy ${ }^{38}$. Cognitive abnormalities were observed in $36 \%$ of cases and oculomotor abnormalities in $52 \%$. In $16 \%$ of cases they were permanent. 


\section{NEUROSURGICAL TARGETS TO CONTROL PAIN AND PSYCHIA- TRIC DISORDERS}

Neurosurgical targets injury to control psychiatric disorders were also used to treat pain only in the late $1940 \mathrm{~s}$ and early $1950 \mathrm{~s}^{39}$. It was believed that decreasing pain emotional aspects was more effective to relieve pain than decreasing perception and sensory discrimination. So, there was pain persistence, but it would lose its annoying character ${ }^{22}$. However, in addition to indifference to pain, other behavioral aspects were changed by lobotomy ${ }^{22}$. The method has become more selective and with less behavioral interference, and procedures were developed consisting in brain cortex resection, called topectomies ${ }^{40}$. These consisted in frontal cortex removal (Brodmann areas 9, 10 and 46) and would decrease anxiety and exaggerated responses to pain without inducing memory and initiative changes, indifference or affective disorders. Frontal cortical resections in patients with rebel thalamic pain in general produce modest effects.

Postero-medial hypothalamotomy $\mathrm{y}^{41}$, cingulotomy $\mathrm{y}^{42}$ and anterior capsulotomy $y^{34}$ are indicated in patients with disabling anxious, depressive and obsessive components not controlled with psychotropic drugs and psychotherapy. Procedures follow the principles of stereotactic surgery. Complications are uncommon, especially after cingulotomy, being that this procedure provides good results in cases of myelopathic pain, spinal cord and cauda equina injuries and nervous roots avulsion. Anterior capsulotomy may relieve $50 \%$ to $75 \%$ of predominantly neuropathic pains in upper limbs.

Anterior cingulotomy controls approximately $84 \%$ of neuropathic cancer pains and approximately $60 \%$ to $66 \%$ of non cancer pains ${ }^{42}$. Best results are obtained in patients with associated psychiatric morbidity ${ }^{43}$. Recurrence is a constant after the fourth post-cingulotomy year. Reoperation with anteriorly located target ( 4 to $5 \mathrm{~mm}$ ahead of initial injury) tends to recover analgesia obtained with the first procedure. Some authors advocate the performance, already in the first approach, of three injuries in line, anteriorly separated by approximately $5 \mathrm{~mm}^{44}$. The appearance of painful and psychiatric symptoms is slow and progressive, giving time for the scheduling of new cingulotomy, although there are reports of suicide as from the first 12 months after surgery.

\section{HYPOPHYSECTOMY OR NEUROADENOLYSIS}

Microsurgical hypophysectomy by transfrontal or transphenoid route, by radiofrequency transnaso-sphenoyd stereotactic $\mathrm{c}^{45}$, by cryocoagulation $^{46}$, by chemical agents ${ }^{47}$ or by radiation ${ }^{48}$ is indicated to treat pain of hormone-dependent and non-dependent cancer pain, as well as NP. Stress analgesia, hormonal ablation, privation of neurotransmitter effect of antidiuretic hormone in nociceptive units, release of nociceptive system activity tonically inhibited by some hipophysary factor, release of stored opioids, are some justifications proposed for pain relief after hypophysectomy. The action mechanism of this procedure is still not clear.

\section{NON-ABLATIVE METHODS}

\section{Invasive neurostimulation}

Electroneuromodulation, or neurostimulation, is one of the most important non-destructive methods to obtain analgesia and its possible adverse effects may be abolished by stimulation decrease or interruption $^{49}$. Its efficacy is directly related to selection of patients, materials and techniques ${ }^{50}$

Invasive neurostimulation involves controlled electric pulses as interaction method with central or peripheral nervous system neuronal circuits by means of implantable stimulation system. This method is used to control untreatable chronic pain especially of neuropathic origin. It is important alternative to ablative surgery or to long term use of analgesics, including opioids. Simplicity and current availability of small devices with diversified and complete controls have brought comfort and efficacy to neurostimulation methods ${ }^{49,50}$.

\section{Spinal cord electrical stimulation (SCES)}

This technique consists in the insertion of electrodes in the posterior epidural space of thoracic or cervical spine ipsilateral to pain (if unilat- eral) at the spinal cord level corresponding to the affected dermatome, to topographically evoke paresthesia sensations in the same region ${ }^{50,51}$. Topographic adjustment was considered pre-requisite for the effect of spinal cord stimulation; however, recently, hybrid high-frequency currents with intermittent peaks, allow desired analgesic responses without paresthesic sensations.

There are two fundamental techniques: cylindrical electrodes inserted by percutaneous route in general under local anesthesia or by means of plate-type electrodes with open posterior surgical access (interlaminar microflavectomy ${ }^{42}$. The latter seems to be more stable in the epidural space and is better in terms of system battery wear. Energy is supplied by a pulse generator implanted and connected to electrodes by subcutaneous cables ${ }^{51,52}$. Technological developments have progressively offered longer life to pulse generator batteries, and some today may reach 25 years $^{53-55}$

Worldwide, the specialty that has implanted and still implants more spinal cord electrical stimulation systems is anesthesiology; however, only percutaneous implant was performed and patients remained without the benefits of plate-type electrodes, until technology could allow it $^{56}$.

Another research objective is compatibility of SCES implanted elements and MRI. New generation electrodes and neurostimulators already allow the use of MRI in patients with such implants ${ }^{57,58}$.

The technique was initially based on spinal cord gate theory for providing preferential stimulation of large and myelinated fibers which in theory would inhibit spinal cord nociceptive afferents ${ }^{59}$. However, experimental studies have excluded this analgesic action mechanism on SCS involving the effect of inhibitory and modulatory spinal cord posterior horn neurotransmitters, in addition to mobilization of posterior spinal ascending pathways to pain-inhibiting brain centers.

There are also described effects of allodynia control, anti-ischemic effects by improving peripheral and heart perfusion, and effects in diseases related to neurovegetative nervous system, such as complex regional pain syndrome. Peripheral nerves injury with consequent distal sensory loss do not exclude its effect, but ascending dorsal spine integrity is probably necessary.

Temporary stimulation test with implanted electrode with external tip is widely used to identify patients in whom pain remains refractory in spite of correct somatotopy of evoked stimulus. Those with satisfactory result are referred to permanent implant. However, this test is not a warranty of long term success for chronic pain ${ }^{55}$. Patients submitted to different previously failed surgical treatments have collected periods of hope followed by delusions and may not want two more procedures (one test and the other for removal or permanent implant).

Most systematic reviews, as well as studies with their own cases, have concentrated in patients with post-laminectomy painful syndromes (PLPS) with approximately $62 \%$ good results, and in CRPS reaching $67 \%$ good results. Reviews show evidence level II in these painful syndromes favoring the technique. There has also been significant improvement in functional capacity and QL. Undesired events were primarily device malfunction, migration $(13.2 \%)$ or electrodes breakage $(9.1 \%)$. Clinical complications were uncommon and mild, in general resolved by removing the device. General infection rate was $3.4 \%^{59,61}$.

Evidences of cases with positive results were found in CRPS II, peripheral nerve injury, diabetic neuropathy, postherpetic neuralgia, peripheral brachial plexus injuries, amputation (stump and phantom limb pain) and partial spinal cord injury.

However, there are also negative evidences of central pain of brain origin, nervous root avulsion and complete spinal cord transection. However, all reports are class IV, thus not allowing final conclusions.

Treating deafferentation pain has always been a major challenge, especially due to the fact that injured tissue integrity restitution cannot be obtained in spite of numerous and promising studies about results obtained by SCS. Part of this difficulty is the nonexistence of a single pattern both for indication and for the implant technique.

Implantable spinal cord stimulation is the most currently studied neurostimulation method, with more relevant evidences of comparative clinical trials. Most studied syndromes have shown positive results with this technique. Recently, there has been major advance in implantable devices with the acquisition of new technologies both for electrodes 
and pulse generators. Although not having final studies using these new technologies, their availability for physicians and patients is a promising land where in the near future we shall have better results and lower complication rates for this therapy ${ }^{59}$.

\section{Electrical stimulation of posterior roots entry zone}

Neuropathic pain is associated to hyperactivity of second order wide dynamic range spinal cord neurons - WDR. A recently published study used animals (rats) submitted to experimental NP model (radiculopathy) based on fifth lumbar root ligation and compared them to a control group (rats submitted to simulated/false without root ligation surgery) ${ }^{60}$. Both groups were submitted to electrical stimulation of dorsal root entry zone - DREZ. There has been decreased injury-induced cell hyperactivity. Attenuation of WDR neuronal activity obtained by DREZ electrical stimulation supports the idea of adopting the method and respective target to treat NP.

\section{Motor cortex electrical stimulation}

Motor cortex stimulation (MCS) is considered promising, especially to treat trigeminal NP and post-stroke central pain syndromes, such as thalamic pain and brachial plexus avulsion, among others ${ }^{21,61-63}$.

Most studies involving MCS focuses on post-stroke and atypical trigeminal neuropathy, for which there are few effective treatments. Poststroke pain responds well to MCS, because approximately two thirds of patients have obtained satisfactory relief. MCS results for trigeminal NP are very interesting, because they show that $75 \%$ to $100 \%$ of patients have obtained good to excellent pain relief. Other groups have also shown pain improvement in less studied syndromes, such as complex regional pain syndrome, with encouraging results in very severely ill patients with therapeutic failure to spinal cord stimulation ${ }^{61-63}$.

Motor cortex stimulation effect depends on electrodes implant target, which apparently should be implanted in motor cortex region corresponding to body segment affected by pain. There are several methods, both for anatomic location of prefrontal gyrus and for motor cortex functional mapping. It is possible to use imaging methods to locate precentral gyrus by stereotactic method or intraoperative navigation. Functional MRI may locate motor cortex area related to the area affected by pain, by means of functional activation.

In the intraoperative period, neurophysiologic somesthetic evoked potential methods are used to locate central sulcus as well as to confirm the target. Addionally, transdural electrical stimulation to map implant site also may be used and gives functional refinement to motor cortex location. In general, facial pain and upper limb pain representation is in cortical convexity of easy access, while lower limb representation is in general located in inter-hemispheric fissure medial face.

Stimulation electrodes may be placed in the epidural space, by craniotomy or trepanation, connected to the pacemaker by an implantable extension. Adjustments are performed by telemetry during ambulatory visits. In the postoperative period, there is in general a test period of stimulation with external generator and, after favorable results, permanent implant is performed as already described. Stimulation parameters described in the literature are very different with amplitudes varying from 0.5 to $10 \mathrm{~V}$, frequencies between 5 and $130 \mathrm{~Hz}$ and pulse width of 60 to $450 \mathrm{~ms}$. When pulse width and frequency are optimized, most investigators increase stimulation intensity during the evaluation period up to $80 \%$ of motor threshold. Others use fixed intensity stimulation without changes along time.

Among described complications, there are intracranial hemorrhages, infection and permanent neurologic deficits. Seizures induction has also been reported depending on stimulation intensity and frequency. However, in general there is no progression or development of epilepsy.

To date, there are no prospective studies with final conclusions on general and specific MCS efficacy. Literature has diverging opinions with regard to surgical technique, stimulation parameters scheduling and patients' selection. However, MCS seems to be a relatively safe and effective neuromodulatory procedure for selected patients ${ }^{62}$.

\section{Deep brain stimulation}

Deep brain stimulation - DBS was the method used to identify intra- cranial structures during neurosurgical procedures. First reports on obtaining analgesia only appeared in the $1950 \mathrm{~s}^{65}$. Approximately 20 years later, there has been the first report on the first experience of chronic thalamic sensory nuclei stimulation to treat $\mathrm{NP}^{66}$. Other authors have reported their long term success with somesthetic thalamic stimulation, and later the target has become periaqueductal (PAG) and periventricular (PVG) gray matter ${ }^{67}$.

A meta-analysis was carried out to determine DBS efficacy to treat chronic pain. Analyzed articles showed long term results totaling 1114 patients ${ }^{67}$. From these, 561 (50\%) had long term pain relief with DBS. Good long term results rate varied between $19 \%$ and $79 \%$, showing loss of efficacy in the long term. A total of 711 patients had NP, of whom $296(42 \%)$ had relief maintained in the long term. From 443 nociceptive pain patients, $272(61 \%)$ had long term success ${ }^{67}$.

DBS complications include intracranial hemorrhage as the most significant and potentially severe. It may appear at electrode insertion or removal time. The incidence of hemorrhage varies between $1.9 \%$ and $4.1 \%$. Current electrodes design has provided significant decrease in the incidence of intracranial hemorrhage. Mortality related to this procedure is uncommon between $0 \%$ and $1.6 \%$. Infectious DBS complications rate varies between $3.3 \%$ and $13.3 \%$. Infections in general affect soft tissues but uncommon cases of nervous system affection have also been described. Most cases require surgical cleaning and device removal, in addition to systemic antibiotics for successful resolution of the infection $^{67}$.

Targets for pain and psychiatric disorders control, such as anterior cingulus or anterior internal capsule portion, might be sites for deep brain stimulation ${ }^{68,69}$. Recently cingulus dorso-anterior DBS has been recognized as feasible target to treat chronic $\mathrm{NP}^{70}$.

Major drawback is withidrawal syndrome caused by disconnecting the generator due to programming error or decreased generator useful charge, which could increase the risk of suicide. Neurosurgery to treat mental disorders is still controversial among lay people, although less in current neurosurgical and psychiatric conceptions. The movement started in Italy in the 1960s, known as Antipsychiatry, is unfortunately still alive, bringing to the fore neurosurgical procedures for pain relief using psychosurgery targets. So, even for patients who had attempted suicide once or more times before being operated on, when this happens after surgery, probable culprit will be surgery. The argument about the non-ablative nature and the concept of method reversibility attenuate opponents' protests, exceptionally lay people $\mathrm{e}^{71-73}$.

DBS has shown its best results to treat cluster headache and nociceptive syndromes, such as chronic low back pain. To treat post-stroke brain central pain, postherpetic neuralgia and myelopathic pain, responses were not satisfactory.

DBS should only be considered after failure of conservative treatments, including less invasive neurostimulation methods.

\section{Intraforaminal dorsal root sensory ganglion electrical stimulation} Neuropathic pain may be localized, needing stimulation concentrated on neural structures related to affected territory innervation. The location of poles on the desired region needs consciousness preservation and patients' cooperation. Laminectory with awaken patients has technical difficulties and, in such conditions, cylindrical electrodes, implanted by percutaneous route were imperative, however with major chance of migration and consequent loss of ideal somatotopy ${ }^{74.75}$.

Analgesic responses obtained with pulsed electrical stimulation applied to dorsal root ganglion suggest the possibility of persistent analgesia by chronically stimulating this structure.

Epidural catheter insertion has always been performed by punctures cranially oriented to prevent their tips to be inserted in foraminal outputs of roots.

Using reverse punctures with cannula and electrode tip caudally oriented, it is feasible to locate poles on dorsal root sensory ganglion with few chances of migration ${ }^{74,75,76}$. There are still few publications on the subject, not allowing a more accurate evaluation, although preliminary results are promising.

Peripheral nerves or field stimulation 
Peripheral nerves stimulation for pain relief was based on the idea derived from popular knowledge that painless stimulation, such as friction or massage, close to skin painful area, would relieve baseline discomfort which, in the 1960s, has received the theoretical support of the Gate Theory, proposed by Melzack \& Wall in the 1960s and afterward the refining of the sensory interaction theory ${ }^{77}$.

Peripheral electrical stimulation for pain treatment is applied worldwide.

Most widely known technique is transcutaneous electrical nerve stimulation (TENS). By means of surface electrodes placed on the affected site or on the pathway of the nerve corresponding to the region, stimulation is performed in high frequency and low intensity (below pain threshold), to predominantly activate large and densely myelinated fibers and induce local paresthesias. Responses of this technique are variable with stimulation sessions lasting 20 to 30 minutes and daily repeated. Pain relief, if present, is immediate but short-lasting, and sometimes is only present during stimulation application ${ }^{77,78}$.

For continuous and more effective application, percutaneous implant of electrodes adjacent to the nerve (peripheral nerve stimulation) or just in its vicinity (subcutaneous field stimulation) has been proposed.

\section{Drug release system implants in the nervous system}

Implantable systems for analgesic drug release in the central nervous system (intraventricular, cisternal and lumbar spine) for refractory pain relief $^{81-83}$, including those of neuropathic predominance ${ }^{84}$, are less complex and require less specific training as compared to stereotactic methods (exceptions are uncommon cases needing intraventricular release in patients with ventricular cleft) ${ }^{81,82}$.

Pumps have a drug reservoir with volumes varying from 12 to $80 \mathrm{~mL}$. They may be mechanically driven, with permanent gases expansion pressure, and by computerized and telemetrically commanded electronic pumping. They may release agents in the spinal, cisternal, intraventricular and epidural space. Epidural release is not routinely used, because although safe with regard to infections, has disadvantages such as the need for higher drug dose, frequent obstruction and frequent catheter displacement ${ }^{82,85-87}$.

Indications for spinal or intraventricular drug infusion are patients refractory to conservative treaments who have: chronic nociceptive or neuropathic pain ${ }^{85,86}$, complex regional pain, cancer pain, post-laminectomy syndrome (failed back surgeries), myelopathic pain, pelvic pain and peripheral neuropathies. Spinal opioid administration associated to adjuvant drugs promotes more than $200 \%$ decrease in the amount of administred oral or parenteral drugs $s^{86,86}$

Targets for spinal route are virtually the same as for oral, sublingual, parenteral or transdermal indications; however, adverse effects are dramatically decreased by spinal route and needed titration for pain control may be reached within hours rather than days decreasing toxicity risk with shorter hospital stay ${ }^{87}$. When pain is predominantly nociceptive, therapeutic targets are opioid receptors, especially type $\mu$, and ligant drugs of choice are opioids. To treat NP, therapeutic targets are type N calcium receptors (ziconotide ${ }^{88-90}$ ), unspecific calcium receptors (mexiletine) gamma-aminobutyric acid or GABA receptors (baclofen, midazolam), alpha-2- adrenergic receptors (clonidine, dexmedetomidine), dopamine receptors (droperidol) and NMDA receptors (methadone, ketamine), among others ${ }^{91,92}$. Drugs association or mixtures are used to improve results ${ }^{93}$.

Successful treatment with pump implants depends on careful patients' selection: estimated survival rate above 6 months, moderate to severe chronic pain (VNS:6-10), exclusion of severe psychological disorders, lack of analgesic response to high oral opioid doses together with adjuvants and analgesic techniques, and previous spinal test with analgesia above $50 \%$ maintained for more than 10 hours ${ }^{93,94}$.

Implant technique for lumbar spine drug release consists in putting patient in the lateral position, preferably the right side, a spinal cannula entry point is marked in the lumbar region, cannula is introduced in the spinal space until CSF is observed. With radioscopic control, the catheter is introduced through the cannula and is fixed in the muscle and subcutaneous (to prevent catheter displacement), tunnelization by the subcutaneous until its connection to the pump lodged in the abdominal region. Implant technique for intraventricular release is similar, being the cannula distal to the pump, implanted inside lateral ventricle (in general right ventricle) by forward trepanation or over the coronary suture, between 2.5 and $3 \mathrm{~cm}$ from the midline ${ }^{82}$.

Most frequent complications of the surgical technique are infection, CSF fistula, catheter disconnection, system malfunctioning, wrong programming, seroma formation, pressure ulcers and granulomas ${ }^{94}$.

\section{CONCLUSION}

Patients eligible for invasive procedures to control neuropathic pain have, in addition to suffering inherent to pain itself, mixed suffering, which includes a collection of repeated delusions at every treatment failure. They have reserved prognosis with regarg to total cure and, unfortunately relief obtained with invasive treatment in general does not reach persistent and high rates. In such adverse situation, these partial results of original pain intensity decrease could be interpreted as acceptable provided impact on QL is positive. Probably, rare exceptions are good results obtained with typical, idiopathic/cryptogenic neuralgias, ironically excluded from the stricter interpretation of the new pathophysiological classification of neuropathic pains.

\section{REFERENCES}

1. Fontaine D, Blond S, Mertens P, Lanteri-Minet M. [Neurosurgical treatment of chronic pain]. Neurochirugie. 2015;61(1):22-9. French.

Oliveira Jr JO. Aspectos referentes à fisiopatologia comparada entre dor neuropática e espasticidade. Rev Dor. 2000;2(1):30-5.

Erdine S. Neurolytic blocks: when, how, why. Agri. 2009;21(4):133-40.

4. Minson FP, Garcia JB, Oliveira Jr JO et al, editors. Tratamento năo farmacológico da dor oncológica, em II Consenso Nacional de dor oncológica. São Paulo: Moreira Jr; 2011. 92-106p.

Oliveira Jr JO, Posso IP, Serrano SC, et al. - Bloqueios Neurolíticos. In: Alves Neto O, Costa CM, Siqueira JT et al. Dor: princípios e prática. Sáo Paulo: Artmed; 2009. 1272-88p.

6. Teixeira MJ, Amorim RLO, Fonoff ET. Tratamento neurocirúrgico funcional ablativo da dor, em: Alves Neto O, Costa CMC, Siqueira JT, Teixeira MJ: Dor princípios e prática, São Paulo: Artmed; 2009. 1219-36p.

7. Corrêa CF. Princípios gerais do tratamento cirúrgico da dor. In: Alves Neto O, Costa CM, Siqueira JT, Teixeira MJ. Dor princípios e prática. Sáo Paulo: Artmed; 2009. 1205-18p.

8. Oliveira Jr JO, Andrade MP, Amaral EM. Dor em oncologia. In: Brentani MM, Coelho FR, Iyeyasu $\mathrm{H}$, et al. Bases da Oncologia. Sáo Paulo: Lemar; 1998.

9. Oliveira Jr JO. Dor oncológica. Acta Oncol Bras. 1994;14(1):11-5.

10. Teixeira MJ, Oliveira Jr JO, Salles AF, Seguchi HH, Gal PL, Almeida GM. Neurotomia por radiofrequência dos ramos recorrentes das raízes lombares. Arq Bras Neurocir. 1983;2(1):39-57.

11. Gusmão $\mathrm{S}$, Magaldi $\mathrm{M}$, Arantes $\mathrm{A}$. [Trigeminal radiofrequency rhizotomy for the treatment of trigeminal neuralgia: results and technical modification]. Arq Neuropsiquiatr. 2003;61(2-B):434-40. Portuguese.

12. Oliveira Jr JO. Rizotomia percutânea trigeminal por radiofrequência. In: Gusmáo S, Castro AB Neuralgia do trigêmeo. DiLivros; 2010. 47-70p.

13. Corrêa CL. Compressão do gânglio trigeminal com baláo. In: Gusmão S, Castro AB. Neuralgia do trigêmeo. DiLivros; 2010. 71-80p.

14. Tew JM. Treatment of pain of glossopharingeal and vagus nerves by percutaneous rhizotomy, in: Youmans JR. Neurological surgery. Philadelphia: Saunders; 1982. 3609-12p.

15. Teixeira MJ. A lesão do trato de Lissauer e do corno posterior da substância cinzenta da medula espinal e a estimulaçáo elétrica do sistema nervoso central para o tratamento da dor por desaferentaçăo. (Tese de doutoramento), São Paulo: Faculdade de Medicina, Universidade de Săo Paulo, 1990.

16. Thomas DG. Dorsal root entry zone (DREZ) thermocoagulation. Adv Tech Stand Neurosurg. 1987;15:99-114.

17. Blumenkopf B. Neuropharmacology of the dorsal root entry zone. Neurosurgery. 1984;15(6):900-3

18. Teixeira MJ, de Almeida FF, de Oliveira YS, Fonoff ET. Microendoscopic stereotactic-guided percutaneous radiofrequency trigeminal nucleotractotomy. J Neurosurg. 2012;116(2):331-5.

19. Chivukula S, Tempel ZJ, Chen CJ, Shin SS, Gande AV, Moossy JJ. Spinal and nucleus caudalis dorsal root entry zone lesioning for chronic pain: efficacy and outcomes. World Neurosurgery. 2015;84(2):494-504

20. Hitchcock E, Teixeira MJ. Pontine stereotactic surgery and facial nociception. Neurol Res 1987;9(2):113-7.

21. Ibrahim TF, Garst JR, Burkett DJ, Toia GV, Braca JA $3^{\text {rd }}$, Hill JP, et al. Microsurgical pontine descending tractotomy in cases of intractable trigeminal neuralgia. Neurosurgery. 2015;11(4):518-29.

22. Fonoff ET, Oliveira Jr JO. Procedimentos invasivos no tratamento da DN. In: DN: avaliaçáo e tratamento. 2012. 137-61p.

23. Tasker RR. Percutaneous cordotomy for persistent pain. In: Gildenberg PL, Tasker RR. Textbook of stereototactic and functional neurosurgery. New York: McGraw-Hill; 1996. 1491-505p.

24. Fonoff ET, de Oliveira YS, Lopez WO, Alho EJ, Lara NA, Teixeira MJ. Endoscopic-guided percutaneous radiofrequency cordotomy. J Neurosurg. 2010;113(3):524-7.

25. Fonnof E, Lopez WO, de Oliveira YS, Teixeira MJ. Microendoscopy-guided percutaneous cordotomy for intractable pain: case series of 24 patients. J Neurosurg. 2016;124(2):389-96.

26. Viswanathan A, Bruera E. Cordotomy for treatment of cancer-related pain: patient selection and intervention timing. Neurosurg Focus. 2013;35(3):E6.

27. Reddy GD, Okhuysen-Cawley R, Harsh V, Viswanathan A. Percutaneous CT-guided cordotomy for treatment of pediatric cancer pain. J Neurosurg Pediatr. 2013;12(1):93-6.

28. Schvarcz JR. Stereotactic extraleminiscal myelotomy. J Neurol Neurosurg Psychiatry. 1976;39(1):53-7.

29. Francisco AN, Lobāo CA, Sassaki VS, Garbossa MC, Aguiar LR. [Punctate midline myelotomy for the treatment of oncologic visceral pain: analysis of three cases]. Arq Neuropsiquiatr. 2006;64(2B):446-50. Portuguese. 
30. Teddy PJ. The role of neurosurgery in the treatment of chronic pain. Med J Aust. 2016;204(8):287-8.

31. Gildenberg PL - Mesencephalotomy for Cancer Pain. In: Lozano AM, Gildenberg PL, Tasker RR -Textbook of stereototactic and functional neurosurgery. New York: Springer; 2009. 2533-40p.

32. Shieff C, Nashold BS Jr. Stereotactic mesencephalotomy. Neurosurg Clin N Am. 1990;1(4):825-

33. Whisler WW, Voris HC. Mesencephalotomy for intractable pain due to malignant disease. Appl Neurophysiol. 1978;41(1-4):52-6.

34. Voris HC, Whisler WW. Results of stereotaxic surgery for intractable pain. Confin Neurol. 1975;37(1-3):86-96

35. Schvarcs JR. Paraqueductal mesencephalotomy for facial central pain. In: Sweet W, Obrador S, Martin Rodrigues JR. Neurosurgical Treatment in Psychiatry Pain and Epilepsy. Baltimore: University Park Press; 1977. 661-7p.

36. Sugita K, Mutsuga N, Takaoka Y, Doi T. Results of stereotaxic thalamotomy for pain. Confin Neurol. 1972;34(1):265-74.

37. Young RF, Jacques DS, Rand RW, Copcutt BC, Vermeulen SS, Posewitz AE. Technique of stereotactic medial thalamotomy with the Leksell Gamma Knife for treatment of chronic pain. Neurol Res. 1995;17(1):59-65.

38. Hitchcock ER, Teixeira MJ. A comparison of results from center-median and basal thalamotomies for pain. Surg Neurol. 1981;15(5):341-51.

39. Freeman W, Watts JW. Psychosurgery in the treatment of mental disorders and intractable pain, in: Springfield IL, Thomas CC. et al. Psycho-chirurgie et Fonctions Mentales. Paris: Masson et Cie; 1954.

Sano K, Mayanagi Y, Sekino H, Ogashiwa M, Ishijima B. Results of stimulation and destruction of the posterior hypothalamus in man. J Neurosurg. 1970;33(6):689-707.

41. Ballantine HT Jr, Cassidy WL, Flanagan NB, Marino R Jr. Stereotaxic anterior cingulotomy for neuropsychiatric illness and intractable pain. J Neurosurg. 1967;26(5):488-95.

42. Talairach J, He Caen H, David M. Lobotomie pre frontale limitee par electrocoagulation des fibres thalamo-frontales a leur emergence du bras antere rieur de la capsule interne. Rev Neurol. 1949;83:59.

43. Cosgrove GR. Cingulotomy for Depression and OCD, in: Lozano AM, Gildenberg PL, Tasker RR. Textbook of stereototactic and functional neurosurgery. New York: Springer; 2009. 2887-96p.

44. Chung SS, Lee HJ, Lee KS, Lee KC, Choi JU. Stereotaxic radiofrequency hypophysectomy for disseminated breast and prostate cancer-transseptal transsphenoidal approach. Yonsei Med J. 1981;22(1):53-7.

45. Duthie AM. Pituitary cryoablation. Anaesthesia. 1983;38(5):495-7.

46. Moricca G, Arcuri E, Moricca P. Neuroadenolysis of the pituitary. Acta Anaesthesiol Belg. 1981;32(1):87-99.

47. Hayashi M, Taira T, Chernov M, Izawa M, Liscak R, Yu CP, et al. Role of pituitary radiosurgery for the management of intractable pain and potential future applications. Stereotact Funct Neurosurg. 2003;81(1-4):75-83.

48. loan PA, Hodes J, John W. Radiosurgical pituitary ablation for cancer pain. J Palliative Care. 1996;12(1):51-3

49. Oliveira Jr JO. Neuroestimulaçáo para controle da dor. In: Nitrini R. Condutas em neurologia. Clínica Neurológica. Saao Paulo: HC/FMUSP; 1991.161-6p.

50. Corrêa FC. Estimulaçáo elétrica da medula espinal para o tratamento da dor por desaferentaçáo. Săo Paulo: Lemos Editorial; 1997.

51. Cameron T. Safety and efficacy of spinal cord stimulation for the treatment of chronic pain: a 20year literature review. J Neurosurg. 2004;100(3 Suppl):254-67.

52. Kinfe TM, Pintea B, Link C, Roeske S, Güresir E, Güresir Á, et al. High frequency $(10 \mathrm{kHz})$ or burst spinal cord stimulation in failed back surgery syndrome patients with predominant back pain: preliminary data from a prospective observational study. Neuromodulation. 2016;19(3):268-75.

53. Deer TR, Mali J. The Future of Neurostimulation. In: Atlas of Implantable Therapies for Pain Management. New York: Springer; 2016. 145-9p.

54. Kiritsy M. Burst stimulation could be the next generation of spinal cord stimulation. Top Pain Manag. 2016;31(1):8-9.

55. Practice guidelines for chronic pain management: An updated report by the American Society of Anesthesiologists Task Force on Chronic Pain Management and the American Society of Regional Anesthesia and Pain Medicine. Anesthesiology. 2010;112(4):810-33.

56. Logé D, De Coster O, Pollet W, Vancamp T. A novel percutaneous technique to implant plate-type electrodes. Minim invasive Neurosurg. 2011;54(5-6):219-22.

57. Levy RM. MRI-compatible neuromodulation devices: critical necessity or desirable adjunct? Neuromodulation. 2016;17(7):619-26.

58. Provenzano DA, Williams JR, Jarzabek G, DeRiggi LA, Scott TF. Treatment of neuropathic pain and functional limitations associated with multiple sclerosis using an MRI-compatible spinal cord stimulator. A case report with two year follow-up and literature review. Neuromodulation. 2016; [Epub ahead of print].

59. Kumar K, North R, Taylor R, Sculpher M, Van den Abeele C, Gehring M, et al. Spinal cord stimulation versus conventional medical management: a prospective, randomized, controlled, multicenter study of patients with failed back surgery syndrome (PROCESS study). Neuromodulation. 2005;8(4):213-8.

60. Yang F, Zhang C, Xu Q, Tiwari V, He SG, Wang Y, et al. Electrical stimulation of dorsal root entry zone attenuates wide-dynamic-range neuronal activity in rats. Neuromodulation. 2015;18(1):33-40. 61. Brown JA, Barbaro NM. Motor cortex stimulation for central and neuropathic pain: current status. Pain. 2003;104(3):431-5.

62. Carroll D, Joint C, Maartens N, Shlugman D, Stein J, Aziz TZ. Motor cortex stimulation for chronic neuropathic pain: a preliminary study of 10 cases. Pain. 2000;84(2-3):431-7.

63. Fonoff ET, Hamani C, Ciampi de Andrade D, Yeng LT, Marcolin MA, Jacobsen Teixeira M. Pain relief and functional recovery in patients with complex regional pain syndrome after motor cortex stimulation. Stereotact Funct Neurosurg. 2011;89(3):167-72.

64. Heath RG - Studies in schizophrenia. Cambridge: Harvard University Press; 1954.

65. Mazars G, Merienne S, Cioloca C. Stimulations thalamiques intermittentes antalgiques. Rev Neurolog. 1973;128:273-9.

66. Kumar K, Toth C, Nath RK. Deep brain stimulation for intractable pain: a 15-year experience. Neurosurgery. 1997;40(4):736-46.

67. Bittar RG, Kar-Purkayastha I, Owen SL, Bear RE, Green A, Wang S, et al. Deep brain stimulation for pain relief: a meta-analysis. J Clin Neurosci. 2005;12(5):515-9.

68. Sakas DE, Panourias IG. Rostral cingulate gyrus: a putative target for deep brain stimulation in treatment-refractory depression. Med Hypotheses. 2006;66(3):491-4.

69. Adams JE, Hosobuchi Y, Fields HL. Stimulation of internal capsule for relief of chronic pain. J Neurosurg. 1974;41(6):740-4.

70. Russo JF, Sheth SA. Deep brain stimulation of the dorsal anterior cingulate cortex for the treatmen of chronic neuropathic pain. Neurosurgical Focus. 2015;38(6):E11.

71. Kendler KS. The nature of psychiatric disorders. World Psychiatry. 2016;15(1):5-12.

72. Adams J. British nurses' attitudes to electroconvulsive therapy, 1945-2000. J Adv Nurs 2015;71(10),2393-401.

73. Wenz H, Wenz R, Groden C, Schmieder K, Fontana J. The pre-interventional psychiatric history - an underestimated confounder in benign intracranial lesions studies. Clin Neurol Neurosurg. 2016;137:116-20.

74. Liem L. Stimulation of the Dorsal Root Ganglion. In: Slavin KV. (editor) Stimulation of the Peripheral Nervous System, The Neuromodulation Frontier. 2016;(29):213-24

75. Bara G, Deer TR. Spinal cord stimulation of the dorsal root ganglion. In. Derr TR, Pope JE. editors Atlas of implantable therapies for pain management $2^{\text {th }} \mathrm{Ed}, 2016 ; 23: 151-9$.

76. Bremer N, Ruby J, Weyker PD, Webb CA. Neuromodulation: a focus on dorsal root ganglion stimulation. Pain. 2016;6(3):205-9.

77. Carroll D, Moore RA, McQuay HJ, Fairman F, Tramèr M, Leijon G. Transcutaneous electrical nerve stimulation (TENS) for chronic pain. Cochrane Database Syst Rev. 2001;(3):CD003222.

78. Meyler WJ, De Jongste MJ, Rolf CA. Clinical evaluation of pain treatment with electrostimulation: a study on TENS in patients with different pain syndromes. Clin J Pain. 1994;10(1):22-7.

79. Weiner RL. Peripheral nerve neurostimulation. Neurosurg Clin N Am. 2003;14(3):401-8.

80. Monti E. Peripheral nerve stimulation: a percutaneous minimally invasive approach. Neuromodulation. 2004;7(3):193-6.

81. Meira UM, Carvalho RR. Intrathecal (IT) use of opioids and non-opioids. In: Cukiert A. Neuromodulation. 2010. 46-60p.

82. Costa AL. Intraventricular use of opioids. In: Cukiert a. Neuromodulation. 2010. 60-6p.

83. Oliveira Jr JO, Lima CH, Serrano SC, et al. A dor no paciente com câncer. In: Kowalski LP, Anell A, Salvajoli JV, et al. - Manual de condutas diagnósticas e terapêuticas em oncologia. 2002. 129-47p.

84. Njee TB, Irthum B, Roussel P, Peragut JC. Intrathecal morphine infusion for chronic non-Malignant pain: a multiple center retrospective survey. Neuromodulation. 2004;7(4):249-59.

85. Krames ES. Intraspinal opioid therapy for chronic nonmalignant pain: current practice and clinical guidelines. J Pain Symptom Manage. 1996;11(6):333-52.

86. Burton AW, Rajagopal A, Shah HN, Mendoza T, Cleeland C, Hassenbusch SJ $3^{\text {rd }}$, et al. Epidural and intrathecal analgesia is effective in treating refractory cancer pain. Pain Med. 2004;5(3):239-47.

87. Upadhyay SP, Mallick PN. Intrathecal drug delivery system (IDDS) for the cancer pain management: a review and updates. Am J Hosp Palliat Care. 2012;29(5):388-98.

88. Oliveira Jr JO. Ziconotide. In: Pimenta CAM, Shibata MK, 8,89, CF - Arquivos $7^{\circ}$ Simpósio Brasileiro e Encontro Internacional sobre dor. 2005. 203-8p.

89. Bäckryd E, Sörensen J, Gerdle B. Ziconotide trialing by intrathecal bolus injections: an open-labe non-randomized clinical trial in postoperative/posttraumatic neuropathic pain patients refractory to conventional treatment. Neuromodulation. 2015;18(5):404-13.

90. Raffaeli W, Sarti D, Demartini L, Sotgiu A, Bonezzi C, Italian Ziconotide Group. Italian registry on long-term intrathecal ziconotide treatment. Pain Physician, 2011;14(1):15-24.

91. Wood AJ. Pharmacologic Treatment of Cancer Pain. N Engl J Med. 1996;335(15):1124-32.

92. Willis KD, Doleys DM. The effects of long-term intraspinal infusion therapy with noncancer pain patients: evaluation of patient, significant other, and clinic staff appraisals. Neuromodulation. 1999;2(4):241-53

93. Doleys DM, Coleton M, Tutak U. Use of intraspinal infusion therapy with non-cancer pain patients: follow up and comparison of worker's compensation vs. non-worker's compensation patients. Neuromodulation. 1998;1(3):149-59.

94. Miele VJ, Price KO, Bloomfield S, Hogg J, Bailes JE. A review of intrathecal morphine therapy related granulomas. Eur J Pain. 2006;10(3):251-61. 